\title{
A DESIRE FOR TRANSPARANCY ON BERENICE ABBOTT'S MILK WAGON AND OLD HOUSES
}

\author{
Steven Humblet ${ }^{1}$
}

In 1939 the New York publisher E.P. Dutton published a photographic book titled Changing New York. The book consists of 97 images made by the American photographer Berenice Abbott (1898-1991) and captions written by Elizabeth McCausland (1899-1965), an American art critic and companion of Abbott. Although many other photographic guidebooks on New York were published that year - on the occasion of the World's Fair of 1939 to be held that year in New York -, this book clearly stood out from the rest. It was a quality product, not produced for the indiscriminate tourist market, but targeting a more sophisticated public. This ambition manifests itself in the layout of the book which neatly separates text and image: the images stand on their own, captured by the surrounding white of the page, untouched by the short captions that are on the opposite page. This serene, almost classical presentation did put the book at odds with the prevailing models for organizing a pictorial book, which required a more lively, and almost cinematic, combination of text and image. Even Abbott and McCausland them-

1 Chargé de cours à Sint-Lukas Brussel.

Recherches en communication, $\mathrm{n}^{\circ} 27$ (2007). 
selves, in the mock-up they initially presented to the publisher, ${ }^{1}$ wanted to organize the book in this cinematic way, but in the end the publisher rejected their proposition and chose instead a far more discrete layout.

Unlike other guidebooks that wanted to show the marvel city that modern New York had become after some decades of "creative destruction', this book reached for a deeper understanding of the logic underlying the frenetically changing city. As so many other pictorial books about the city, written accounts of its history, and even institutions (museums and historical societies) that dealt with the history of New York City, the book presented 'change' as the defining quality of modern New York City. In a city where real estate developers were incessantly 'building, unbuilding, and rebuilding' the city, it seemed only natural to suppose that New York was a city in constant flux, continuously reshaping its architectural forms and rearranging its neighbourhoods. ${ }^{2}$ Still, Changing New York did something more than present the frictions between the 'old' and the 'new', it also tried to show how even in the midst of this turmoil the modern city remained legible. Abbott's insightful images present modern New York as a system, not just as a haphazard collection of buildings, roads and railroad tracks. Her carefully composed pictures seem to suggest that there was a web that kept this whole city together. Whether this network was a construction woven by real people or an abstract system that secretly guided the actions of thousands or millions of people, was not important: the point is that Berenice Abbott (and a lot of other people) thought of this city as a (semi)conscious construct. This viewpoint implied that it was possible to make sense of this city, that it was possible to grasp by means of photography the system that supported this gigantic, ever changing, ever growing 'thing'.

To understand how these images were capable of telling the very complex and layered reality of modern New York, I would like to analyse one image made by Berenice Abbott. Although this particular image, 'Milk Wagon and Old Houses', is not part of the book, it's quite revealing of the way in which the photographer tried to concentrate

1 B. YOCHELSON, Berenice Abbott: Changing New York, New York, The New Press, 1997.

2 M. PAGE, The Creative Destruction of Manhattan 1900-1940, Chicago, University of Chicago Press, 2000, p. 232. 
as much information in one image as possible. Abbott's book did not contain all the images that were made for the project 'Changing New York' (in total she made 308 images, the book contains 'only' 97). Moreover, not one of the images was especially made for the book: it was an (almost accidental) offshoot of a more encompassing project. ${ }^{1}$

\section{Changing New York: a WPA project}

Already in her first letter, dated November $16^{\text {th }}$, 1931, Abbott herself ascribed a certain plan, or mission, to her project. She turned to Mr. Scholle, the then director of the Museum of the City of New York (and from 1935 also a member of the Federal Arts Project New York City advisory committee) in the hope of gaining some institutional (and financial) support:

I propose (...) making a documentary interpretation of New York City in photographs, setting down many of the fast disappearing records of early New York which have and will have increasing historical value. The city is still greatly uncrystallized and is in the making. To record what remains of its early and various influences, its dramatic contrasts, its rapid state of flux emerging into one big form that is New York is (...) of great importance for the future archives of this city. Only photography can catch the swift surfaces of cities today. When the proper medium of photography will have been understood, it will be recognized as having most descriptive literary value and to be most suitably adapted to the recording of historical facts. ${ }^{2}$

With this first attempt at describing what would later become her project 'Changing New York' several crucial (albeit conflicting) notions are brought together. It has to become a documentary that deals with historical facts destined for the archives, but at the same time, it should also be an interpretation with literary value. An interpretation, but still dealing with facts, descriptive but at the same time literary... This hotchpotch of ideas contains some of the key concepts of the docu-

1 The book was as much the result of Abbott's raising public success as of the FPA's desperate need for favourable publicity. See B. YOCHELSON, op. cit., 1997.

2 Letter from Berenice Abbott to Hardinge Scholle, dated november 16th, 1931. Archive of the Museum of the City of New York. 
mentary style as developed by Walker Evans. By emphasizing these elements, however, Abbott hoped to distinguish her project from other photographic inventories of the city of New York, projects that were also considered to be of a documentary nature. There was for instance the registration of every house in New York by the Tax Administration, which photographed each building in New York from the front and from the back. Moreover, photographer Percy Loomis Sperr set out to capture this thriving metropolis in no less than 10.000 images on behalf of the New York Public Library. To mark the difference of her project with these ongoing projects, Berenice Abbott made three statements. First, the project was to be artistic (whatever that means), which would distinguish her images from those taken by order of the Tax Administration. Secondly, the project would focus almost entirely on the architecture of the city - architecture was considered to be one of the most important means the community used to represent itself - in other words, her project had nothing to do with street photography which was the photographic genre in which Percy Loomis Sperr was working. The third claim however was the most important one: her project was to be a carefully organized attempt to give an account of the changes that transformed contemporary New York. This was not just a photographer roaming about in the streets of New York and taking haphazardly pictures, this was on the contrary a photographer with a plan and a mission ${ }^{1}$.

In 1935, after years of trying to secure some financial endorsement, Berenice Abbott (finally) received a rather considerable support from the Federal Arts Project, a subdivision of the Work Progress Administration, one of the governmental organisations founded during the New Deal. Although she did not get everything she asked for, the support she did receive was more than enough to continue her project for more than three years. For the most part she was supported financially: she received a monthly allowance, which made it possible for her to work full-time at her project. She also received considerable material support: a car to make for lighter and easier travel throughout the city and two assistants to help her with the large and heavy photographic equipment she used. This rather generous (and for that time certainly unique) support gives us an idea of the far reaching goals

1 O. LugOn, Le style documentaire. D'August Sander à Walker Evans. 1920-1945, Paris, Macula, 2001, pp. 86-88 
of the images, the scope of their ambition and the way it resonated with some deeply felt cultural and artistic convictions of that time. Although no written account exists of why the FPA accepted Abbott's proposal, we can assume that one reason was that both parties believed the idea that photography was able to do more than just reproduce an existing situation, but that it was also capable of performing an intelligent analysis of the inner workings of the city. Still, this widespread belief in the power of photography did not refrain the FPA from questioning this ambitious program. Their concerns were not directed at the medium, but rather at the notion of 'documentary' by which Abbott tried to define the specificity of her project. In general, they wondered how each of these images could guarantee their information value. In a city that was so swiftly changing, where whole blocks seemed to disappear overnight, they considered it necessary to add a written account to the image ${ }^{1}$. Apparently, the FAP did not believe that the photographic image in itself was transparent enough to secure a stable reading, but that it was to be completed by a text that would explain what the picture was about ${ }^{2}$.

To meet this documentary goal they assigned several researchassistants to Abbott's project. Their task had a double nature: first to identify the buildings and important objects in the picture and secondly to describe how the objects or buildings function within the larger fabric of the city. These texts convey a kind of encyclopedic knowledge: besides all kinds of factual data (name of original and current owner of building, name of architect, the date it was built, the precise address where it was located, the original cost and the contemporary value of the building, etc.), most of these research files also contain a short text in which background information is given (about the history of the building, about the people who live there, etc). With regard to a picture of a gas station for instance the researcher explains in great detail how such a gas station functioned. The texts have a very straight-

1 See undated letter to Berenice Abbott concerning 'Suggestions in connection with the information, data and write-up to accompany Berenice Abbott's photographic series'. Archive of the Museum of the City of New York.

2 As such, this way of working was not entirely new, even I.N. Phelps Stokes in his highly influential The Iconography of Manhattan Island (published in 1928), relied heavily upon an elaborate group of researchers to research the background history of each image in his Iconography. See M. PAGE, op. cit., p. 227. 
forward didactic function. They help the viewer understand what the image is about. In other words: these texts explain why the world is how it is. As such they give the viewer amidst the storm of change the pleasant impression that he is still able to grasp this fleeting world.

For the presentday researcher these research files are very important. More than ever, they provide vital information that allows us to broaden our understanding of these images and how they relate to the volatility of the city. These files were written after the pictures were taken. In other words, they are not the result of preliminary research done by Abbott herself, but they consist of comments and analyses 'after the fact'. They refer to the world through the prism of an image and the researchers look at the world through the lens of a camera. These research files are therefore of a double nature: as such they don't seem to tell us anything about the reasons why Abbott chose to photograph this or that scene, or even for that matter about the formal choices of the photographer (the formal choices of Abbott are with some exceptions never questioned in these files). They deal with the 'what' rather than with the 'how' of the picture. Nonetheless, precisely because the researchers develop their analysis on the basis of what the image shows, their gaze is guided by the formal choices made by the photographer. Thus, in retrospect, these texts do reveal something of the prior objectives of the photographer, albeit in a skewed manner.

\section{'Milk Wagon and Old Houses': an analysis}

At a first glance 'Milk Wagon and Old Houses' seems a rather straightforward image: it shows a milk wagon still being pulled by a horse and in the background there are some old houses. Within the broader context of 'Changing New York' this image could be understood as the last reminder of an economic practice that is about to disappear, just as the old houses in the background are doomed to be replaced by something new (and probably something bigger). Even Abbott's framing of the image, aggressively cutting the horse in half, strengthens this interpretation. It is as if the horse already belongs for the most part to the past, as if it is chopped up and fed to the past. Reading the image in this way makes it part of a larger group of images that deal with things of the past, with buildings and practices that are slowly but 


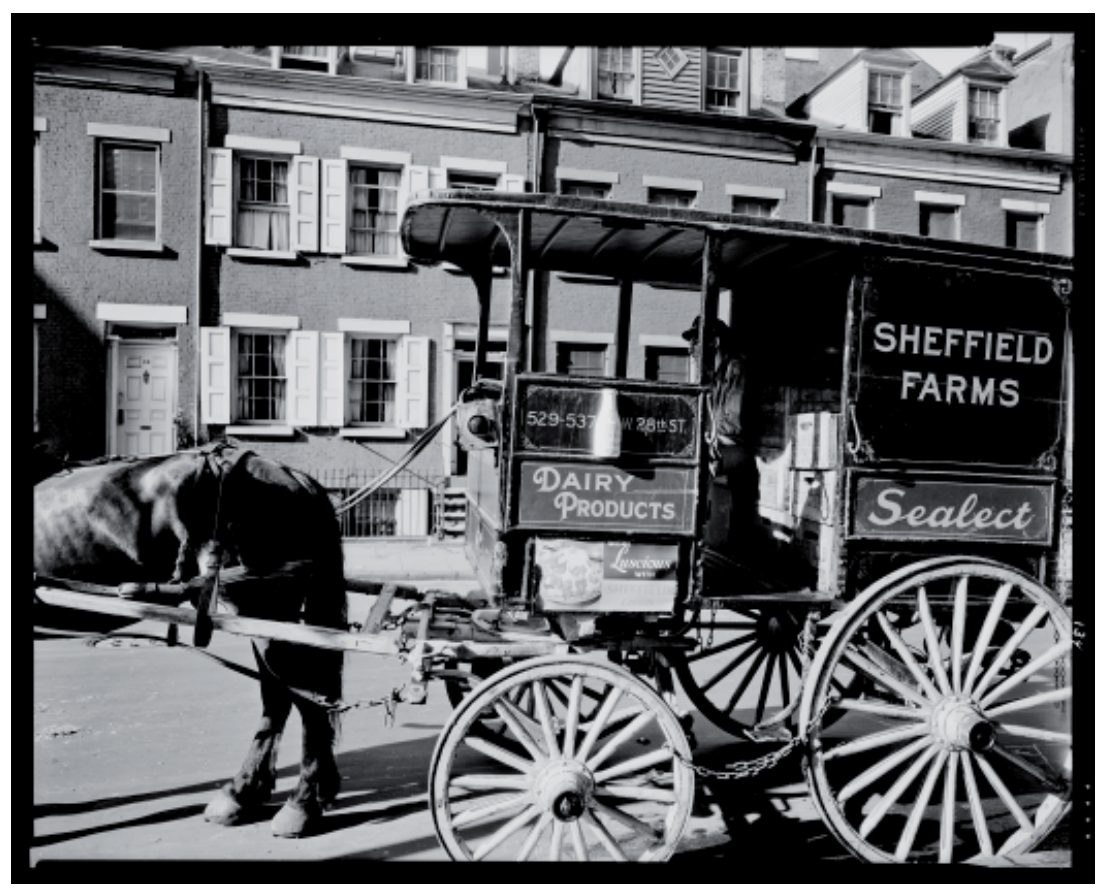

Berenice Abbott, Milk Wagon and Old Houses (1939) Courtesy by Museum of the City of New York

surely disappearing. This image, so it seems, is nothing more than a mere reflection of how things once were, it is a document of a present becoming rapidly the past. Anyway, this is how I read this image the first time I encountered it.

To gain access to at least one other dimension of this image, the concept of 'readability' as developed by Olivier Lugon in his remarkable book on the documentary style is instructive. In Le style documentaire, Lugon regards 'readability' (or 'lisibilité') as a crucial concept of this photographic style. Like other key concepts specific to the documentary style, 'luminosity', 'sharpness', and 'frontality', the 'readability' of the photographic image was supposed to guarantee its transparency'. The concept of 'readability' however is a rather complex one: it not only

1 O. LUGON, op. cit., pp. 189-214. 
means that the content of the image has to be directly legible and easily discernible - the viewer has to be able to grasp the content immediately -, but it means also that the image should be read as a text. This second aspect seems to contrast with the demand of transparency. To read an image means to decipher it, to scrutinize it in every detail and in doing so to make sense of it. To engage the viewer in such an attitude of careful attention, the documentary photographer tends to integrate at least some textual information in the image itself. Whereas in the case of photojournalism for instance every image needs a legend to explain what it is about, in the case of documentary photography the legend is in a certain way already imbedded in the image itself (you could even say that it is tattooed on the skin of the object). That's also the reason why these images don't need elaborate texts to accompany them. In Changing New York, the captions that accompany the images literally repeat what can be seen in the image. There is an absolute equivalence between the two media: the text never says something that is not visible in the image. What the caption often does, is prescribing a route through the image: now you see this, than you see that and finally we end here.

In the image 'Milk Wagon and Old Houses' there are indeed some words visible. At first, these words only seem to have one function, to emphasize once more that this is indeed a milk wagon (as if the object is labeled). But if we take a closer look, another history appears and some other, hitherto unnoticed, dimension of the image comes to light.

For the viewer of 1939 'Milk Wagon and Old Houses' is not only an image of an old milk wagon, but it also refers to a fierce economical struggle of that period. Abbott carefully framed the image in such a way as to include the name of the milk distributor 'Sheffield Farms' (which was not essential because the more general term 'dairy products' sufficed to make sure that the viewer could identify what he saw). By including this name she made a clear reference to a social-economical issue. Sheffield Farms was in fact one of the two (or three) most important milk distributors in the city of New York. Together with Borden's Farm Products they controlled the production, distribution and sale of dairy products: in 1938 it was estimated that Sheffield Farms was in control of over 60 percent of the market. From 1931 onwards however the state and city administration tried to gain some control over this market, a response to a public outcry against the sharp rising prices of a product that was considered to be of vital importance. These adminis- 
trations installed in 1933 the Milk Control Board to try to curb the rising prices by setting a maximum and minimum retail prize (the so-called 9 cents milk). But this state intervention was considered too intrusive and as a result a lot of lawsuits ensued, all the way up to the American Supreme Court. In other words: the tension between two conflicting political models becomes tangible in this battle over the milk price. One that kept the government out of the economy, and another one that wanted to give the government some leverage in organizing the economic principles that ruled the marketplace.

This state intervention ended eventually in an internal fight between farmers and the distribution sector. Outbursts of violence between these opposing groups became very common between 1931 and 1939: there were even two fatalities (to give a general impression of the importance of the matter). Especially the farmers had great trouble swallowing the measures of the Milk Control Board, because the dairy dealers kept their profit margins and the farmers had to carry the price cut all by themselves. In this way, the name of the company on the photograph sufficed to remind the contemporary public of this struggle and its different political and socio-economical ramifications. Besides opposing political programs, the image encloses the economical forces that sustain the free market and their continuously shifting relation. The result is that this image loses its tranquility and, in a certain sense, its obsoleteness. It is no longer a nostalgic look into a lost world, characterized by a certain pace and speed (or rather lack of speed), but instead becomes a highly charged and explosive image that deals with some very fundamental social issues. Through choosing this object and including it in her project, Abbott invited the public to a political and social-economical reading of her project. To put it in a more general way, this image (along with others) can be read as an attempt to materialize the more invisible (and yet very decisive) forces that shape the city.

It's important to note however that this shift in meaning is in no way accidental or superficial, but that it is consciously prepared by the formal choices made by the photographer herself. These 'hidden' dimensions of the image are not read into the image (as a result of the consultation of this research file in the archive), but are already present in the image itself. In such a way even that the research file can be seen (and read) as something that provides the necessary answers to questions raised by the image. The story told by the researcher is 
not a figment of his imagination, but is a thoughtful response to the issues introduced by the picture that is lying before him. Abbott framed the image in such a way that one single detail becomes the focus of the image: the bottle of milk that has been carefully maneuvered to the center of the image. As if Abbott wants to point the viewer in the direction of the central topic of this image. This picture is not at all about the horse-pulled milk wagon, but about a bottle of milk. Another important formal aspect is the conspicuous flatness of the image. There is no real depth in the image (you can not even measure the precise distance between the milk wagon and the houses on the background). Everything is intricately linked, only two elements detach themselves from that dark background: the white words on the milk wagon and that exploding white spot of the milk bottle. ${ }^{1}$ Text and bottle jump into vision and declare themselves as the real subject of the photograph.

So far, we've overlooked but one visible element that is the other breathing creature, the milkman. Nevertheless, this person too pops up in the text of the researcher. In a short but very intriguing passage the researcher tries to describe the attitude of the milkman, who drives around with a milk wagon to deliver the goods at every doorstep. No matter how tentative and strange this extract may seem and how easily it could be discarded as a poetical exaggeration, I think we can and have to take it seriously. I am not really interested in the truthfulness of the researcher's account. For instance when he maintains that the horse driven milk wagon will not disappear in the near future, he was obviously misled, attaching too much credence to what the milkmen told him. Indeed, hardly one year after this text was written Sheffield Farms would build a large distribution centre for their dairy products and the horse pulled wagons would vanish almost immediately and would be replaced by delivery trucks. ${ }^{2}$ What is of great interest to me in this short passage is that the author presents the milkman as the incarnation of another dimension of the city. In these few sentences the milkman embodies a certain experience of the city, a way of moving through the city that is tightly linked to his profession.

1 With thanks to Jay Bochner and Luca Acquareli for their valuable remarks during the discussion after my lecture.

2 B. YOCHELSON, op. cit., The New Press, 1997, pp. 364-365. 
(...) the city delivery is still in the horse and buggy age, and bids fair to so remain until motor cars through some technique of remote control are taught to 'follow the route', while the 'routeman' (as “milk-men" are most puctiliously called in this trade) makes his deliveries through the basements and over the roof-tops of the town. (...) Dobbin knows the 'route' and can be depended on to be at a given place at a given time - when the routeman will emerge with mole-like perspicacity from some half-hidden basement, replenish his trays and disappears again, while Dobbin keeps to the 'route'. ${ }^{1}$

Both the milkman and the horse are engaged in a regular and unvarying performance; they're performing a routine. Day after day they successively visit various points and places in a fixed order. In their experience the city resembles an intricately structured universe, a mole-like network of intersecting tunnels. However complex the system may seem, the milkman and his horse keep a general overview. To them the city remains transparent. Their vision of the city closely resembles the desire for transparency that characterizes the documentary photography. The concept of readability always supposes that a solution can be found, regardless how difficult the riddle might be. This eagerness for readability manifests itself in the rigid composition of the image. Everything is kept together by a dominant center: the bottle of milk. The horse, the milkman, the inhabitants of the houses on the background, and even the viewer, are all in the grasp of the vicissitudes of the milk, or more precise, of the man-made laws governing the production and distributing of milk. By including the milkman and his commanding vision on the city, the image suggests that it is still possible to get a clear understanding of the inner workings of our daily environment.

\section{Conclusion: the need for a thick description}

Whenever a picture is taken, we have the impression that the object that is in front of the camera gets abducted to a flat surface and is immediately reduced to a graphical play of lines and volumes. The object loses its consistency and becomes an empty shell, a flattened surface. However, as my analysis of Berenice Abbott's 'Milk Wagon and Old

1 See research file on 'Milk Wagon and Old Houses'. Archive of the Museum of the City of New York. 
Houses' has shown, the object that is transferred to the picture plane is more than just an empty form, it is already filled with meaning. It's this 'thickness' of the object that interests the documentary photographer. All the formal choices he of she makes are aimed at arousing this slumbering narrative richness of the photographed object. Every analysis of a photographic image has therefore to deal with this stubborn presence of the object in the photographic image, and cannot limit itself to a careful reading of the image alone and its (lack of) aesthetic qualities. In my analysis of Berenice Abbot's image 'Milk Wagon and Old Houses', I tried to clarify how the interpretation of this image requires a thick description, ${ }^{1}$ which examines the photograph and the object it depicts within the broad cultural context in which both operate. Even when we consider the photographic image as an object with a social life,$^{2}$ we should not forget that the object in the photograph is also an object with a social life and that the two together take the viewer on a swirling round dance.

1 I'm referring here to the notion of 'thick description' as coined by Gilbert Ryle and later elaborated by Clifford Geertz, who understands it as an '(a)nalysis (...) sorting out the structures of signification (...) and determining their social ground and import'. C. GEERTZ, The Interpretation of Cultures, New York, Basic Books, 1973, p. 9.

2 See E. EDWARDS and J. HART, "Introduction: Photographs as Objects", in: E. Edwards and J. Hart (ed.), Photographs Objects Histories. On the Materiality of Images, New York/London, Routledge, 2004. 